\title{
Uni-Representational Vs. Cross-Representational Difference in Imagery Formation: Verification of Dual Coding Theory
}

\author{
Anwesha Chakrabarti ${ }^{1}$, Dr. Amrita Panda ${ }^{2}$, Prof. Mallika Banerjee ${ }^{3}$
}

\section{ABSTRACT}

Dual coding theory states that information is stored by visual and verbal channel separately. During formation of imagery the visual and verbal channels are used distinctly. The study explores how retrieval of visual imageries of natural scenes varies with the variation in representational forms of encoding and recognition. Each stimulus set contained two different cards for encoding and recognition purpose. Both encoding and recognition of visual scenes were varied in both pictorial (picture form) and linguistic (word form) mode. Thus four plausible conditions are pictorial encoding associated with pictorial recognition, pictorial encoding and linguistic recognition; linguistic encoding and linguistic recognition and lastly, linguistic encoding with pictorial recognition. The aim of the study is to see whether the mode of object representation influences imagery formation. The aim of the study is to explore which kind of representation benefits recognition of imagery. 40 female University students (21 to 23 years) were selected and randomly assigned in to four experimental conditions. From each participant data was collected in the laboratory set up in a single session. Nine stimulus cards were presented to each subject. Presentation of a single stimulus card in encoding situation was followed by the recognition situation. The two way ANOVA result shows changing the representational forms has significant effects on retrieval. The present finding supports the notion of Dual coding hypothesis with an additional observation that poor retrieval in case of pictorial recognition when the information has been encoded linguistically.

Keywords: Visual imagery, Pictorial representation, Linguistic representation, Dual coding approach, Encoding retrieval match

The dual coding theory hypothesises cognition involves two distinct subsystems namely verbal and nonverbal which are specialized in processing linguistic and pictorial materials, respectively

\footnotetext{
${ }^{1}$ Department of Psychology, University of Calcutta, Kolkata, West Bengal, India

${ }^{2}$ Department of Psychology, University of Calcutta, Kolkata, West Bengal, India

${ }^{3}$ Department of Psychology, University of Calcutta, Kolkata, West Bengal, India

*Responding Author

(C) 2016, I A Chakrabarti, A Panda, M Banerjee; licensee IJIP. This is an Open Access Research distributed under the terms of the Creative Commons Attribution License (http://creativecommons.org/licenses/by/2.0), which permits unrestricted use, distribution, and reproduction in any Medium, provided the original work is properly cited.
} 


\section{Uni-Representational Vs. Cross-Representational Difference in Imagery Formation: Verification of Dual Coding Theory}

and together connected with referential link. They function independently as well as cooperatively. A number of researches have been conducted to verify the relative strength of each of the subsystems. There are ample evidences for establishing the superiority of nonverbal systems. Paivio, 2006 noted that pictures are more concrete and thus beneficial for memory. The additive property of dual coding theory as explained by Paivio makes the pictorial materials mnemonically stronger (Paivio \& Lambert, 1981). Begg (1972) confirmed the conceptual peg hypothesis by saying that concrete phrases are integrated in memory by images. This result was also consistent in Sadoski's (1985) study on children where the participants had to report verbally what kind of imagery he could form during hearing a story having dramatic climax. Sadoski concluded that the climax image acts as a conceptual peg for subsequent recall of the remaining story. Prior memory researches draw somewhat contradictory view regarding this. Although the schema theorists have an alternative explanation, i.e., deep and distinct processing of concrete material, supported by contextual cues which help in its better recall, the neurological and other theoretical evidences support the dual coding theory. Thompson \& Paivio (1994) showed that object pictures and sounds have additive effect on memory. Brain scan studies also summarize that left hemisphere is more responsible for processing of verbal materials and right hemisphere is more responsible for nonverbal stimulus processing. Moeser and Bregman (1973) supported dual coding theory by establishing that syntax correlated referent pictures are beneficial for rapid learning. This result was also reassured by Purnell and Solman (1991) in similar studies.

Pylyshyn (1973) countered Paivio's notion of dual coding by postulating a single abstract mode of internal representation. Kosslyn et al. (1976) showed that when the effect of rehearsal and imageablity competes, rehearsal wins, thus, rehearsed words are better recalled than imaged words. Rather, his research supports the paradigm of 'depth of processing' by Craik \& Lokhart (1972). A number of researchers attempted to test the modality specificity of dual coding theory, and they conclude the existence of distinct modality for processing of different mode of information (Brooks, 1967, 1968 ; Segal \& Fusella, 1970; Kosslyn, 1976). Penney (1975) opined that modality specificity had an effect on short term memory but not on long term memory. However, it is a widely researched area and yields contradicting evidences. Some research showed no effect of modality (e.g., Challis et al., 1993; Nelson, Balass, \& Perfetti, 2005), some showed audio mode is superior to visual (e.g., Curran \& Dien, 2003; Hintzman \& Caulton, 1997; Maylor \& Mo, 1999), and still other concluded visual is better than auditory modality (e.g., Hayman \& Rickards, 1995; Penney, 1989). Kosslyn further stated that rather than dual coding of object representation, image formation improve recall by semantic elaboration. Some researchers found no significance of mutual interference between visual perception and recall of words imaginally (Elliot, 1973; Bower et al., 1972; Brooks, 1970). Two separate studies by Anderson (2000) and Bransford \& Franks (1971) showed linguistic encoding is more long 


\section{Uni-Representational Vs. Cross-Representational Difference in Imagery Formation: Verification of Dual Coding Theory}

lasting than perceptual encoding for better semantic association. Thus earlier studies drew inconclusive evidence regarding the form of encoding.

All the researches aiming at verification of dual coding hypotheses used verbal material requiring acoustic processing and pictures requiring visual processing. Although we find a handful studies in the area of modality specificity, but not much conclusive evidences in the area of transfer of information through referential link from pictorial to linguistic and vice versa in the same modality.

The encoding specificity hypothesis suggests that in order to produce a successful retrieval the retrieval cue must be a part of encoded information at the time of storage (Thompson and Tulving, 1970). A much related but not identical concept in this regard is the idea of encodingretrieval match. Researches on state-dependent, mood-dependent and context- dependent memories established support for the encoding- retrieval match theory (Roediger \& Guynn, 1996; Smith \& Vella, 2001). Further support came from later experimental findings on the role of colour in memory (Spence et al., 2006), influence of encoding- retrieval on prospective memory (Hannon \& Daneman, 2007), etc. Parallel to this theory the neurological explanation given by reinstatement theory (Johnson \& Rugg, 2007) also refers to the encoding retrieval match hypothesis. The 'cue overload' explanation states that more the number of cues associated with a specific cue, the effectivity of that cue declines (Craik and Jacoby (1979). Counter evidences by Nairne (2001, 2002, 2012) challenged the encoding specificity theory and encoding retrieval match by saying that it enhances performance only for the fact that it increases the cue's power as target comparing with its any other competitor. According to this view the diagnostic value of cue is the key for retrieval. As delineated by Nairne (2001, 2002, 2005, 2006, and 2012) cuing may increase, hinder or be unable to make any change on performance, depending on the diagnostic value (nature) of the cuing.

The present study aims at finding out the effect of verbal and pictorial processing of stimulus material both at the time of encoding and retrieval. It differs from the earlier studies in the ground that within the same modality (visual) it investigates how imagery formation is contributed by the encoding- recognition representational variation. The representational form has been varied in both pictorial (picture based) and linguistic (word based) forms for both the encoding and recognition stimulus conditions. Thus it yields four different experimental conditions: pictorial (encoding) - pictorial (recognition), pictorial (encoding) -linguistic (recognition), linguistic (encoding) - pictorial (recognition) \& linguistic (encoding) -linguistic (recognition). Another objective of the study is to find out whether the uniform (same representational form in encoding and retrieval) or the cross form (opposite representational forms in encoding and retrieval) are beneficial for imagery formation. 


\section{Uni-Representational Vs. Cross-Representational Difference in Imagery Formation: Verification of Dual Coding Theory}

\section{METHOD}

Both pictorial and linguistic representation of scenic description stimulates imagery formation. Description of such scenery involves the prior perception and existing conceptions regarding some specific places. It involves representing something as a unified whole in the mental screen. This experiment uses a number of 'scenery' as the stimulus materials regarding the formation of mental imagery of some unified whole. The response was collected through recognition of objects as were shown in stimulus cards. Thus, each form of pictorial and linguistic encoding was combined with pictorial and linguistic form of recognition process. Accordingly, four experimental conditions results out of the plausible combination of them.

\section{Experimental Design}

A between group design was used. Four groups were randomly selected, each containing 10 participants, for the four experimental conditions. The four conditions were varied in terms of encoding- recognition representations. In the first condition the subject encodes pictorially and recognizes objects from a pictorial form. In the second condition the subject encodes the same set of imagery material pictorially and recognizes linguistically. In $3^{\text {rd }}$ and $4^{\text {th }}$ conditions the participants encode the parallel linguistic form and recognize objects from the pictorial and linguistic forms respectively. In each condition nine stimulus cards were prepared as encoding material and another nine cards for recognition stimulus. The latter (recognition stimulus) was the parallel forms of the previous one only having same amount of distracters. The content of each nine encoding cards were scenery having 8 distinct objects (e.g. house, tree, bird etc) and the recognition forms contain these eight objects in addition with another eight objects (distracter). Each card (both encoding and recognition set) was prepared in two different forms: pictorial and linguistic. They were varied in four experimental conditions in different combinations as stated above.

\section{Participants}

Participants comprised of 40 female young adults ( Age mean= 21.64 years, $\mathrm{SD}=0.9$ ) of Kolkata, India. All the subjects were pursuing post graduation in the same discipline. Participants were briefed about the nature of the study and informed consent was obtained. They were randomly assigned to four experimental conditions. No complain of visual acuity was reported by the participants as per their verbal report. All the participants were matched on the basis of educational qualification, age, gender, mother tongue and geographical location.

\section{Tool used}

For the four experimental conditions 36 cards were prepared in the following manner (diagram 1). All the cards contain either forms of linguistic or pictorial description of some scene of nature. Nine such sceneries were made and varied in four different sets in accordance with the demand of four experimental conditions. Pictorial forms were made with achromatic pencil

(C) The International Journal of Indian Psychology, ISSN 2348-5396 (e) I ISSN: 2349-3429 (p) | 140 


\section{Uni-Representational Vs. Cross-Representational Difference in Imagery Formation: Verification of Dual Coding Theory}

sketches and linguistic forms were written in achromatic pen, both in a white background of A4 papers. The relative locations of each object were kept constant in both of the forms. All the objects used in the cards were very much familiar and non ambiguous as were judged by a preliminary sample of 8 individuals. This was further verified by the verbal reports of the participants in each condition after collection of data.
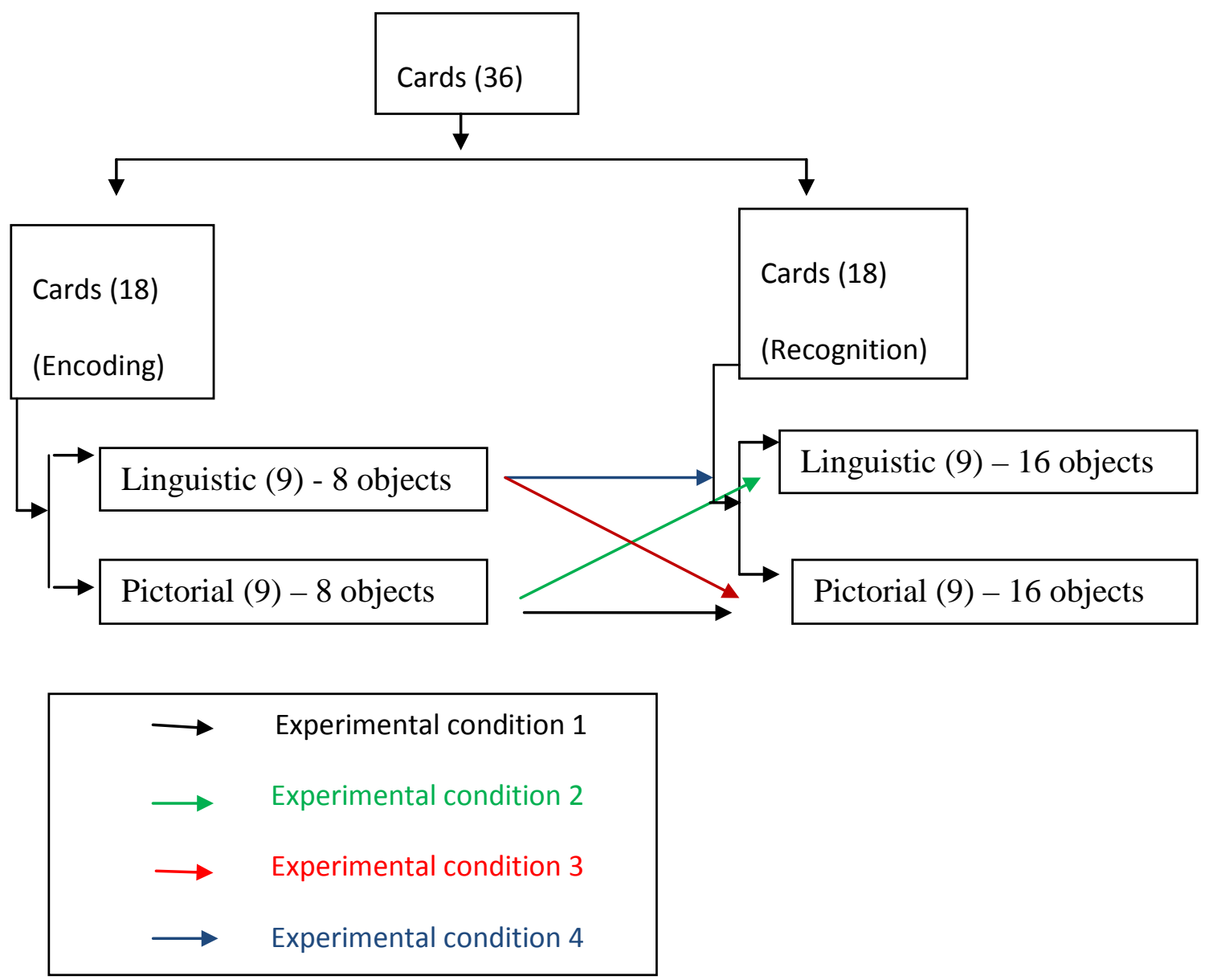

\section{Diagram 1}

\section{Procedure}

All the participants were selected through incidental sampling technique. They were randomly assigned to four experimental conditions. Each group received only one experimental condition. In each condition at first they were shown the first encoding stimulus card (either linguistically or pictorially) for 10 seconds. They were instructed to form an imagery regarding it. Providing three minutes rest they were given the recognition card and asked to identify the additional objects (destructors). After that the $2^{\text {nd }}$ encoding stimulus card was given. The same procedure was followed till the exposure of $9^{\text {th }}$ pair of cards. After completion a written report was

(c) The International Journal of Indian Psychology, ISSN 2348-5396 (e)| ISSN: 2349-3429 (p) | 141 


\section{Uni-Representational Vs. Cross-Representational Difference in Imagery Formation: Verification of Dual Coding Theory}

collected from each participant and where necessary verbal report was also taken for further probing.

Each of the four groups received the treatment conditions in the same manner with uniform exposure time; inter condition temporal gap and sequence of stimulus cards presentation. Data were collected from the four groups separately.

The dependent variable measure was accuracy, determined by the number of correct response. The obtained data were then statistically analyzed by two way Analysis of Variance to see effect of encoding mode (Pictorial and Linguistic) on imagery recognition task, effect of recognition mode (pictorial and linguistic) on imagery recognition and the interaction between the variation of encoding and recognition. In addition further analysis was done to see the effect of uniform (encoding and recognition modes were same) versus cross form representation (encoding and recognition modes were different) and pair wise comparison was done between two uniform levels and two cross form levels. For each condition the mean of correct responses for each card among ten subjects in each condition are regarded as raw scores.

\section{RESULTS}

A 2x2 factorial design was used to see the effect of encoding mode (Pictorial Vs Linguistic) and recognition mode (Pictorial Vs Linguistic) on imagery recognition. Descriptive statistics were computed and to test the significance of differences between means 2x2 ANOVA model was used (Table 1). Levene's test of Homogeneity of variance shows no significant difference ( $\mathrm{F}=0.116)$ in homogeneity of error variance among the four groups. To compare between the mean of imagery recognition scores in uniform (encoding and recognition in same mode) and cross form (encoding and recognition are in different mode) conditions independent $t$ test was used (Table II). Further, pair wise comparison between each two conditions within the uniform and cross form situations was done by computing t test (Table III).

\section{Table I}

$\begin{array}{ccccc}\text { Encoding } & \text { Recognition } & \text { Mean } & \text { SD } & \text { F } \\ \text { Pictorial-Pictorial } & 6.26 & 0.59 & 18.23^{* *} & \text { (Pic Vs Ling encoding) } \\ \quad \text { linguistic } & 6.01 & 0.63 & 8.35^{* *} & \text { (Pic Vs Ling recognition) } \\ \text { Linguistic- } & & & & \\ \quad \text { pictorial } & 4.46 & 0.72 & 16.11^{* *} \text { (encoding* recognition) } \\ \quad \text { linguistic } & 5.95 & 0.66 & & \\ { }^{* *} \mathrm{p}>01 . & & & \end{array}$


Uni-Representational Vs. Cross-Representational Difference in Imagery Formation: Verification of Dual Coding Theory

Table II, Difference between uniform and cross form of recognition on visual imagery

\begin{tabular}{|c|l|l|l|l|l|}
\hline Condition & N & Mean & SD & t value & $\begin{array}{l}\text { Levene's test for } \\
\text { equality of } \\
\text { variance (F) }\end{array}$ \\
\hline $\begin{array}{c}\text { Uniform } \\
\text { representation }\end{array}$ & 18 & 6.1056 & .6264 & $3.058 * *$ & $5.72^{*}$ \\
\hline $\begin{array}{c}\text { Cross form } \\
\text { representation }\end{array}$ & 18 & 5.2333 & 1.0353 & & \\
\hline
\end{tabular}

Notes. ${ }^{*} \mathrm{p}>.05,{ }^{* *} \mathrm{p}>.01$

Table III, Pair- wise comparison within the Uniform and the cross form conditions:

\begin{tabular}{|l|l|l|l|l|}
\hline Condition & Encoding- retrieval & Mean & SD & t \\
\hline Uniform & Pic- pic & 6.26 & 0.59 & \multirow{2}{*}{1.02} \\
\hline Cross Form & Ling- ling & 5.96 & 0.66 & \\
\hline & Pic- ling & 6.01 & 0.64 & \multirow{2}{*}{$4.875^{* *}$} \\
\cline { 1 - 2 } & Ling- pic & 4.46 & 0.72 & \\
\hline
\end{tabular}

Result shows when encoding and recognition both are in pictorial form the retrieval score is highest followed by pictorial form of encoding associated with linguistic form of recognition. The lowest score is obtained by the condition where linguistic form of encoding is associated with pictorial form of recognition. The ANOVA result indicates that both the mode of encoding \& recognition has significant effect on imagery recognition at .01 level. The interaction between the two factors also comes to be statistically significant at .01 level.

Considering the recognition part whether pictorial or linguistic recognition is easier to the participants, it is seen that the mean of linguistic recognition is higher than that of pictorial recognition, showing that it is easier to the participants to respond in linguistic mode perhaps because it is more conceptual and lacks specifications and minute detailing.

Comparison between the uniform vs cross form representation that uniform representation is superior in recognition of images than cross form representations. This mean difference is also significant at .01 level in independent sample t test. [The corrected value of df is 27.975 (instead of 34) as the levense's test is significant at .05 level (Table II)]. The pair wise comparison shows that the mean difference between two levels of uniform representation was not statistically significant and the mean difference between two levels of cross form representation is significant

(C) The International Journal of Indian Psychology, ISSN 2348-5396 (e)| ISSN: 2349-3429 (p) | 143 


\section{Uni-Representational Vs. Cross-Representational Difference in Imagery Formation: Verification of Dual Coding Theory}

at .01 level with a higher score in pictorial encoding associated with linguistic recognition than the other condition i.e. linguistic encoding with pictorial recognition.

\section{DISCUSSION}

The result shows that the retrieval score is highest when the information is encoded pictorially and recognition objects were also represented in pictorial form. This result is consistent with the dual coding theory apparently. Paivio said the pictorial memory is better than linguistic counterpart. Later researches additionally supported the same hypothesis(Paivio \& Lambert, 1981; Begg 1972; Sadoski, 1985). When information is encoded pictorially they are better recognized than that of the condition when information is linguistically encoded and recognized in pictorial form.

Considering the type of encoding it is seen that pictorial encoding is significantly differing from linguistic encoding. So, for encoding, more concrete and specified form of stimulus is desirable for better recognition of visual imagery. Here the divergent production of thinking amounts least. In contrast, if the recognition forms are compared, then we see the linguistic form of recognition is beneficial than pictorial recognition form for better visual memory. The reason may lie in the fact that after encoding information is stored conceptually in more abstract and general form but the physical attributes of the image tends to fade. This explanation was evidenced in the theory of memory trace which suggests that the traces of memory gradually fade with time. But when the information is conceptually processed it is stored by the abstract feature (as Paivio \& Kosslyn coined the term 'propositional file' information). So when the recognition form is linguistic, then participants find it easier to retrieve on the basis of conceptual category rather than physical features.

Moreover, uniformity in mode of encoding and recognition yields better result than processing in distinct mode. More specifically, when information is both encoded and retrieved in pictorial (or linguistic) form, it yields better result than in the condition where information is encoded in one form (e.g. pictorial) and retrieved in another form (e.g. linguistic) and the reversed. This difference is also significant in post hoc analysis at .01 level.

The Encoding retrieval match theory suggests the extent to which encoding and retrieval condition matches better the retrieval results. The present result is consistent to it. Encodingrecognition matched forms were better performed and it needed no transformation from one subsystem to the other. Both linguistic form in encoding \& recognition and pictorial form in encoding \& recognition produced almost equivalent result and the difference between the two conditions was not statistically significant (Table 4). It is more consistent with encoding retrieval match theory rather than dual coding hypothesis. In contrast to Paivio's finding (Paivio \& Lambert, 1981), here the pictorial form is no more beneficial in imagery recognition. The study

(C) The International Journal of Indian Psychology, ISSN 2348-5396 (e)| ISSN: 2349-3429 (p) | 144 


\section{Uni-Representational Vs. Cross-Representational Difference in Imagery Formation: Verification of Dual Coding Theory}

also supports encoding specificity theory in the sense that the form of encoding itself acts as a cue. When the cue is functional at the time of storage then it increases the likelihood of correct recognition.

The study also reveals when the cross representational condition appears in encoding and recognition level, the result reflects variable findings. It shows when pictorial stimulation is provided followed by the linguistic recognition task the result is no different from the uniform representational condition. But when linguistic encoding is given with pictorial recognition task, the performance deteriorates markedly and the difference is significant at .01 level (table 4). So, the transformation from linguistic to pictorial was not as smooth as the transformation of information from pictorial to linguistic. It helps to conclude that although the refential link acts in both ways it varies in strength according to the forms of encoding. The answer lies in the dual coding theory itself. Paivio \& Lambert (1981) said that pictures are mnemonically superior to language, and are more concrete, thus form better imagery. But the present finding shows that when linguistic encoding is followed by linguistic recognition, the result reflects no difference from pictorial encoding and recognition. This is probably because of the fact that the matching of encoding and retrieval conditions creates no hindrance in image formation process. In both the cases subjects found their imaged object that was created in encoding condition again the recognition condition. In other words encoding recognition match took place. The difference is only significant in between two cross representational situations. Here, the result shows that pictorial encoding paired with linguistic recognition facilitates imagery formation in comparison to linguistic encoding associated with pictorial recognition. The probable interpretation is during linguistic encoding the image is formed by top down processing and thus, led the participants to visualize each object by their preconceived experience. Those formed images of objects did not match entirely with the stimulus presented in the recognition condition. The shape of house, nature of trees, posture of birds as imaged by the participants (divergent thinking) did not match exactly with the ones produced in recognition condition. And the result was failure in recognition of the particular objects. Thus, in other words, non image ability is not the key factor for deficient retrieval, rather imaging through divergent thinking leads to a cognitive confusion in recognition task. On the other hand in case of pictorial ending associated with linguistic recognition, the stimulus is presented in specific form and recognition takes place in general form. Here the role of bottom up processing is more crucial. Thus explanation by dual coding theory may be insufficient here to understand the process. Rather, encoding specificity hypothesis and encoding-retrieval match theory explains the following findings more convincingly. More the retrieval cues matches with encoding situations more it leads to better retrieval. 


\section{Uni-Representational Vs. Cross-Representational Difference in Imagery Formation: Verification of Dual Coding Theory}

To summarize from the above experiment we may say that analyzing the end result, Dual coding theory may seems to be appropriate but analysis by process shows greater applicability of encoding retrieval match theory and encoding specificity principle in image formation task.

\section{Acknowledgement:}

AC thanks to

1. Indian Council of Medical Research for financial assistance

2. Students of Post graduation of psychology, in Department of Psychology, University of Calcutta for assistance in data collection

\section{REFERENCES}

Anderson, J. R. (2000). Cognitive psychology and its implications (5th ed.). New York: Worth.

Begg, I. (1972). Recall of meaningful phrases. Journal of Verbal Learning and Verbal Behavior. 11, 431-439.

Bower, G. H., Munoz, R., \& Arnold, P. G.(1972) On distinguishing semantic and imaginal mnemonics. Unpublished manuscript, Stanford University.

Bransford, J. D., \& Franks, J. J. (1971). The abstraction of linguistic ideas. Cognitive psychology, 2, 331-350.

Brooks, L. R. (1967). The suppression of visualization by reading. Quarterly Journal of Experimental Psychology,19, 289-299.

Brooks, L. R. (1968) Spatial and verbal components of the act of recall. Canadian Journal of psychology,22, 349- 368.

Brooks, L. R. (1970) Visual and verbal processes in internal representation. Paper presented at Salk Institute, LaJolla, California, July.

Challis, B. H., Chiu, C., Kerr, S. A., Law, J., Schneider, L., Yonelinas, A., et al. (1993).Perceptual and conceptual cueing in implicit and explicit retrieval. Memory, 1, 127-151.

Craik, F. I. M., \& Jacoby, L. L. (1979). Elaboration and distinctiveness in episodic memory. In. L.-G. Nilsson (Ed.), Perspectives on memory research: Essays in honor of Uppsala University's 500th anniversary (pp. 145-166). Hillsdale, NJ: Erlbaum

Craik, F. I. M., \& Lockhart, R. S.(1972) Levels of processing: A framework for memory research. Journal of Verbal Learning and Verbal Behavior,11, 671-684.

Curran, T., \& Dien, J. (2003). Differentiating amodal familiarity from modality-specific memory processes: An ERP study. Psychophysiology,40, 979-988.

Elliott, L. (1973). Imagery versus repetition encoding in short- and long-term memory. Journal of Experimental Psychology, 100, 270-276.

Hannon, B., \& Daneman, M. (2007). Prospective memory: The relative effects of encoding, retrieval, and the match between encoding and retrieval. Memory, 15, 572-604. doi:10.1080/09658210701407281 


\section{Uni-Representational Vs. Cross-Representational Difference in Imagery Formation: Verification of Dual Coding Theory}

Hayman, C. A. G., \& Rickards, C. (1995). A dissociation in the effects of study modality on tests of implicit and explicit memory. Memory \&Cognition, 23, 95-112.

Hintzman, D. L., \& Caulton, D. A. (1997). Recognition memory and modality judgments: A comparison of retrieval dynamics. Journal of Memory and Language, 37, 1-23.

Johnson, J. D., \& Rugg, M. D. (2007). Recollection and the reinstatement of encoding-related cortical activity. Cerebral Cortex, 17, 2507-2515. doi:10.1093/cercor/bhl156

Kosslyn S.M., Holyoak K. J., \& Huffman C. S. (1976). A Processing Approach to the Dual Coding Hypothesis. Journal of Experimental Psychology: Human Learning and Memory, 2 (3).

Maylor, E. A., \& Mo, A. (1999). Effects of study-test modality on false recognition. British Journal of Psychology, 90, 477-493.

Moeser, S. D. \& Bregman, A. S. (1973). Imagery and language acquisition. Journal of Verbal Learning and Verbal Behavior, 12, 91-98

Nairne, J. S. (2001). A functional analysis of primary memory. In H. L. Roediger, J. S. Nairne, I. Neath, \& A. Surprenant (Eds.), The nature of remembering: Essays in honor of Robert G. Crowder. Washington, DC: APA.

Nairne, J. S. (2002). The myth of the encoding-retrieval match. Memory,10, 389-395.

Nairne, J. S. (2005). The functionalist agenda in memory research. In A. F. Healy (Ed.), Experimental cognitive psychology and its applications (115-126). Washington, DC: American Psychological Association.

Nairne, J. S. (2006). Modeling distinctiveness: Implications for general memory theory. In R. R. Hunt \& J. Worthen (Eds.), Distinctiveness and memory. New York: Oxford University Press.

Nairne, J. S., Poirier M., Morin C., Zimmermann., F. G. S., Koutmeridou K., \& Fowler J. (2012). Memory as Discrimination: A Challenge to the Encoding-Retrieval Match Principle. Journal of experimental psychology: learning, memory and cognition, 38(1), 16-39.

Nelson, J. R., Balass, M., \& Perfetti, C. A. (2005). Differences between written and spoken input in learning new words. Written Language and Literacy, 8, 101-120.

Paivio, A. (2006). Mind and its evolution; A dual coding theoretical interpretation, Mahwah, NJ: Lawrence Erlbaum Associates, Inc.

Paivio, A., \& Lambert, W. (1981). Dual coding and bilingual memory. Journal of Verbal Learning \& Verbal Behavior, 20, 532-539.

Penney, C. G. (1975). Modality effects in short-term verbal memory. Psychological Bulletin, 82, 68-84.

Penney, C. G. (1989). Modality effects in delayed free recall and recognition: Visual is better than auditory. Quarterly Journal of Experimental Psychology: A. Human Experimental Psychology, 41, 455-470.

Purple, K. N., \& Solman, R. T (1991). The influence of technical illustrations on students' comprehension of geography. Reading Research Quarterly, 26, 277-299. 


\section{Uni-Representational Vs. Cross-Representational Difference in Imagery Formation: Verification of Dual Coding Theory}

Pylyshyn, Z. W.(1973) What the mind's eye tells the mind's brain: A critique of mental imagery. Psychological Bulletin,80, 1-24.

Roediger, H. L., III, \& Guynn, M. J. (1996). Retrieval processes. In E. L. Bjork \& R. A. Bjork (Eds.), Memory: Handbook of perception and cognition (2nd ed., pp. 197-236). San Diego, CA: Academic Press.

Sadoski, M. (1985). The natural use of imagery in story comprehension and recall: Replication and extension. Reading Research Quarterly, 20, 658-667.

Segal, S. J., \& Fusella, V. (1970) Influence of imaged pictures and sounds on detection of visual and auditory signals. Journal of Experimental Psychology,83, 458-474.

Smith, S. M., \& Vela, E. (2001). Environmental context-dependent memory: A review and a meta-analysis. Psychonomic Bulletin \& Review, 8,203-220. doi:10.3758/BF03196157

Spence, I., Wong, P., Rusan, M., \& Rastegar, N. (2006). How color enhances visual memory for natural scenes. Psychological Science, 17, 1-6. doi:10.1111/j.1467-9280.2005.01656.x

Thompson, V., \& Paivio, A. (1994)._ Memory for pictures and sounds: Independence of auditory and visual codes. Canadian Journal of Experimental Psychology, 48, 380-398.

Thomson, D. M., \& Tulving, E. (1970). Associative encoding and retrieval: Weak and strong cues. Journal of Experimental Psychology, 86, 255-262. doi:10.1037/h0029997

\section{Figure Captions.}

Diagram 1: Diagrammatic representation of description of cards used in four experimental conditions.

Figure 1: Graphical representation of percentage of correct recognition of visual imagery of experimental groups in respective conditions.

Figure 2: Graphical representation of mean of correct recognition in visual imagery in pictorial and linguistic encoding.

Figure 3: graphical representation of mean of correct recognition of visual imagery in both pictorial and linguistic recognition.

Figure 4: graphical representation of mean of correct recognition of visual imagery in uniform and cross form representations. 
Uni-Representational Vs. Cross-Representational Difference in Imagery Formation: Verification of Dual Coding Theory

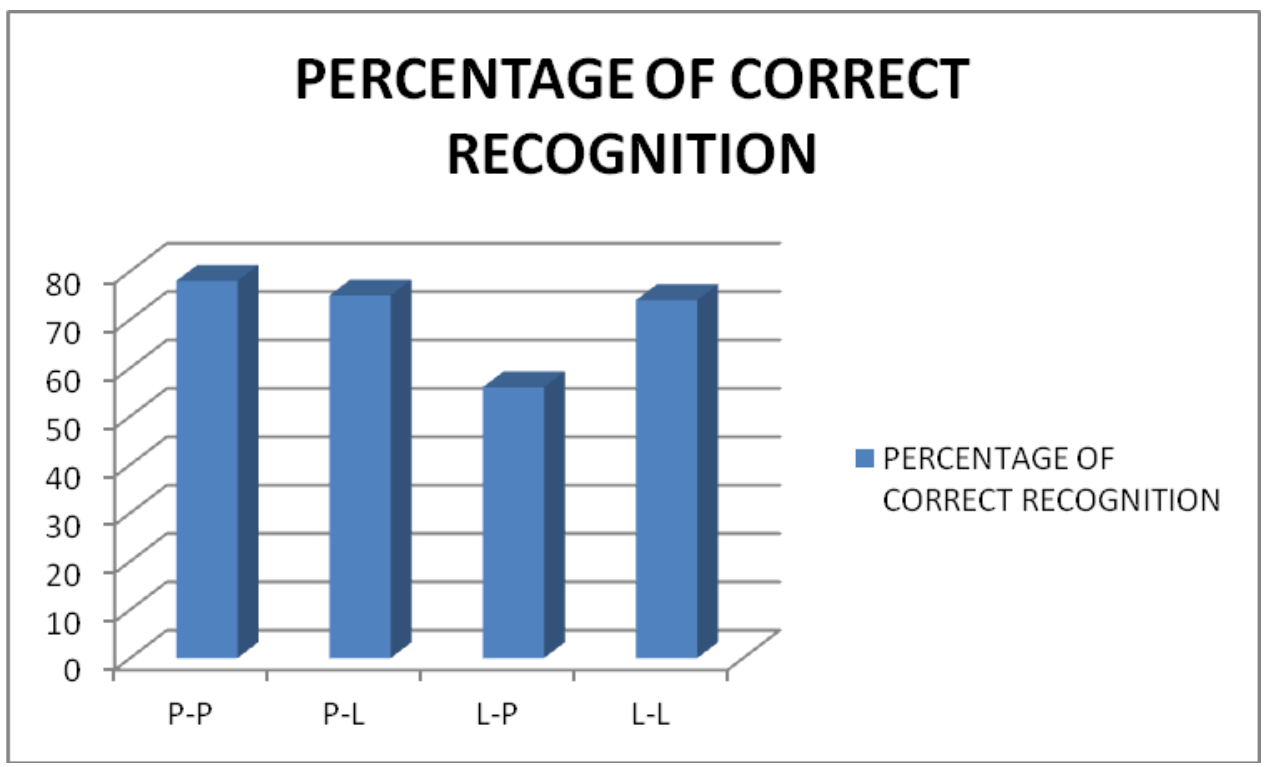

Figure 1

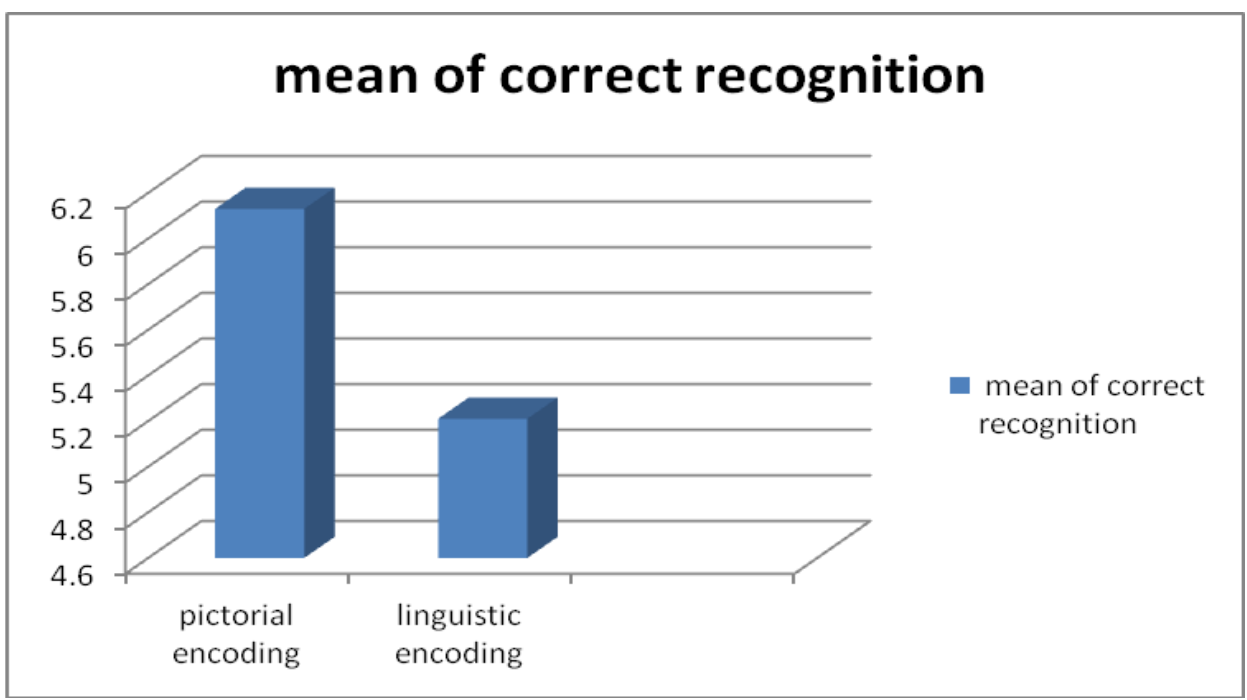

Figure 2

(c) The International Journal of Indian Psychology, ISSN 2348-5396 (e)| ISSN: 2349-3429 (p) | 149 
Uni-Representational Vs. Cross-Representational Difference in Imagery Formation: Verification of Dual Coding Theory

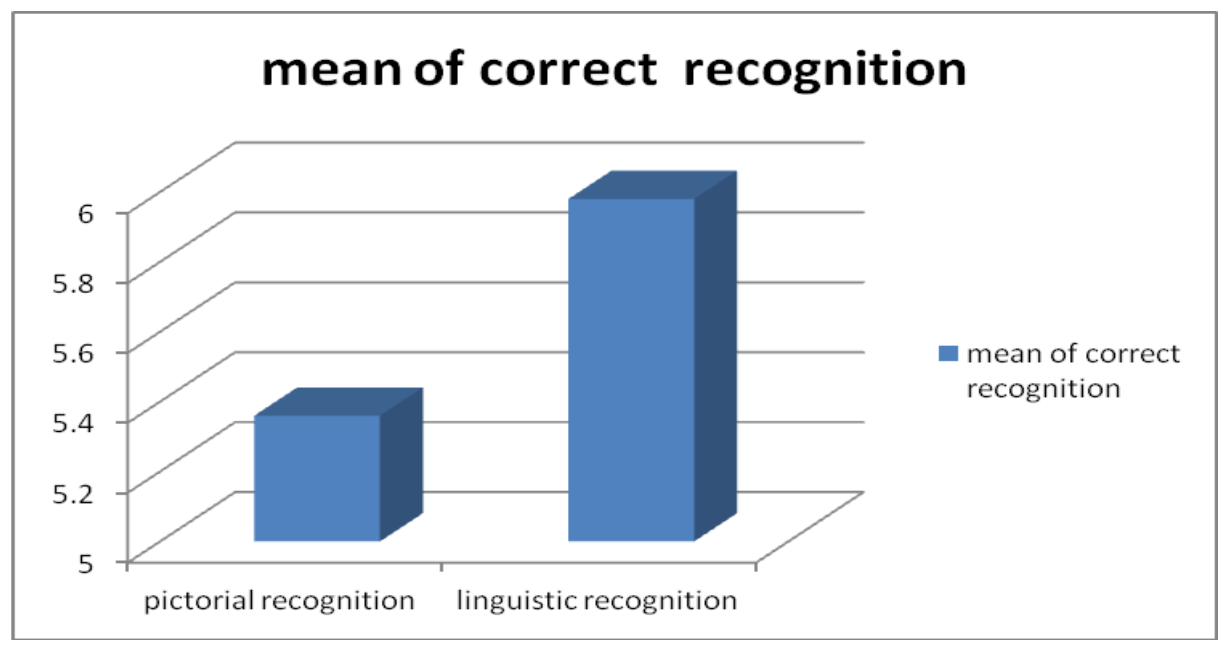

Figure 3

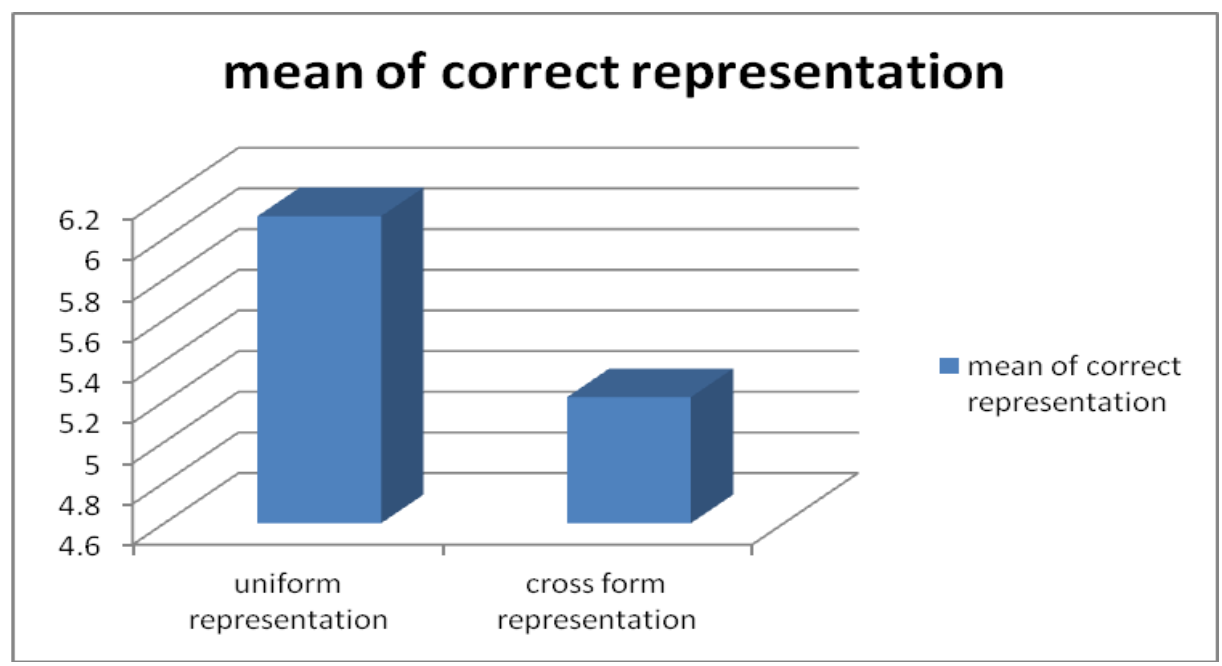

Figure 4

How to cite this article: A Chakrabarti, A Panda, M Banerjee (2016), Uni-Representational Vs. Cross-Representational Difference in Imagery Formation: Verification of Dual Coding Theory, International Journal of Indian Psychology, Volume 3, Issue 4, No. 65, ISSN 2348-5396 (e), ISSN: 2349-3429 (p), DIP: 18.01.146/20160304, ISBN: 978-1-365-34680-4

(c) The International Journal of Indian Psychology, ISSN 2348-5396 (e)| ISSN: 2349-3429 (p) | 150 